\title{
Development and test of hydraulic driven remote transporter
}

\author{
Jiaxue Li ${ }^{1,2}$, Shanjun $\mathrm{Li}^{1,3,4,5,6 *}$, Yanlin Zhang ${ }^{1,3,4,5,6}$, Mingdi Liü ${ }^{2}$, Zhiyuan Gao ${ }^{2}$ \\ (1. College of Engineering, Huazhong Agricultural University, Wuhan 430070, China; \\ 2. Guangdong Polytechnic college, Zhaoqing 526000, Guangdong, China; \\ 3. China Agriculture (Citrus) Research System, Wuhan 430070, China; \\ 4. Key Laboratory of Agricultural Equipment in Mid-lower Yangtze River, Ministry of Agriculture and Rural Affairs, Wuhan 430070, China; \\ 5. Citrus Mechanization Research Base, Ministry of Agriculture and Rural Affairs, Wuhan 430070, China; \\ 6. National R\&D Center for Citrus Preservation, Wuhan 430070, China)
}

\begin{abstract}
To solve the problems of the traditional orchard conveyor, such as inflexible steering, a complex structure, poor stability and no power grid coverage, a remote-controlled rail conveyor powered by hydraulic pressure for mountainous orchards was designed and manufactured. Climbing stress analysis was carried out on a full-load trailer to obtain the maximum traction force, which met the requirement of the climbing slope of the transport mechanism. The key components of the conveyor were developed, such as the hydraulic transmission, the control system, safety protection devices, limiting devices, the throttle and decompression actuator, the counterweight tension and the battery. Through the theoretical calculations of key components, an orchard conveyor powered by diesel and hydraulic pressure was designed. Finally, the working performance of the transporter was tested through functionality, driving speed, system pressure and remote-controlled tests. The test results showed that the climbing angle of the transporter can reach $50^{\circ}$, the uphill load can reach $840 \mathrm{~kg}$, the downhill load can reach $1100 \mathrm{~kg}$, and the average running speed is $0.77 \mathrm{~m} / \mathrm{s}$; the driving speed ranges from $0.29 \mathrm{~m} / \mathrm{s}$ to $1.08 \mathrm{~m} / \mathrm{s}$, and the system pressure ranges from 3.2 MPa to $10 \mathrm{MPa}$. The driving speed and system pressure are significantly affected by the load, and the remote control distance can reach $455 \mathrm{~m}$. The technical specifications of the transporter meet all the design requirements, and the problem of stable operation of the transporter without power grid coverage has been addressed. The research results can well meet the practical application requirements of mountain orchard transportation without power grid coverage and provide theoretical reference for the design of key components of mountain orchard transportation machinery.

Keywords: mountain orchard, conveyor, hydraulic drive, remote control
\end{abstract}

DOI: $10.25165 /$ j.ijabe.20211402.5844

Citation: Li J X, Li S J, Zhang Y L, Liu M D, Gao Z Y. Development and test of hydraulic driven remote transporter. Int J Agric \& Biol Eng, 2021; 14(2): 72-80.

\section{Introduction}

The standardized production of mountain orchards in developed countries is advanced, the regional layout is reasonable, the degree of mechanization is high, the labor intensity is low, and the economies of scale are remarkable ${ }^{[1]}$. Most of the orchards in China are located on hills and mountains, with relatively small-scale production and little standardized production, which can limit the use of machinery and equipment. Their production can be characterized as manual, with high labor intensity, a low degree of mechanization, high production costs and low efficiency $^{[2-4]}$. With the continuous improvement of the national economy, the fruit agricultural development situation is very good in China, but the continuous transfer of the rural labor force to "non-agricultural" sectors will necessitate mechanized orchard

\section{Received date: 2020-04-03 Accepted date: 2020-10-17}

Biographies: Jiaxue Li, MS, Lecturer, research interests: Orchard machinery, Email: lijiaxuevip@163.com; Yanlin Zhang, Professor, research interests: Orchard machinery, Email: zhangyl@mail.hzau.edu.cn; Mingdi Liu, MS, Lecturer, research interests: Orchard machinery, Email: 413795696@qq.com; Zhiyuan Gao, MS, Lecturer, research interests: Orchard machinery, Email: 593481226@qq.com.

*Corresponding author: Shanjun Li, PhD, Associate Professor, research interests: technology and equipment for mechanized production of fruits. College of Engineering, Huazhong Agricultural University, Wuhan 430070, China. Tel: +86-13071289256, Email: shanjunlee@mail.hzau.edu.cn. transportation ${ }^{[5-8]}$.

In recent years, with continued support for the agricultural industry and the continuous improvement of modern agricultural technology in China, experts and scholars of the modern agricultural (citrus) industry system have achieved notable development in orchard transporters ${ }^{[9-13]}$. Hong et al. ${ }^{[10,11]}$ designed and produced a mountain orchard freight lift for oranges and installed it in orchards in Longmen County, Guangdong Province and Anyuan County, Jiangxi Province, achieving maximum productivity of $6.8 \mathrm{t} / \mathrm{h}$ through field tests. Li et al. ${ }^{[2,13]}$ developed a 7YGS-45 self-propelled dual-orbit orchard transporter, focusing on solving the problems of the friction drive with the combination of wire ropes and driving wheel pairs. The demonstration project construction and test were carried out in Yandengbao Village, Guojiaba Town, Zigui County, Yichang City, Hubei Province. The research team of Zhang et al. ${ }^{[14-16]}$ developed a self-propelled remote-controlled monorail transporter for mountain orchards, which enabled the transporter to stop reliably on the track and realize robotic driving. Meng et al. ${ }^{[17,18]}$ designed and manufactured a remote-controlled trackless transporter with a simple construction process and a low cost, which was tested in a citrus garden in Anyuan County, Ganzhou City. There are also scholars who have optimized the transmission efficiency of orchard transporters. Liu et al. ${ }^{[19,20]}$ established a meshing model between a driving wheel and a track rack based on dynamic theory, and selected the best comprehensive 
performance of a sprocket rack. Liu et al. ${ }^{[21]}$ designed a two-way chain transmission system based on worm and gears, which improved the mechanical efficiency of battery-driven transport equipment. A series of transport conveyors designed by domestic scholars suitable for the operation of mountain orchards in China have been promoted and used to varying degrees. These conveyor systems have effectively improved the transportation mechanization level of mountain orchards in China ${ }^{[22]}$.

Existing transport conveyors mainly adopt a combination of mechanical and electromechanical transmissions to control the transport vehicle manually or remotely. In practical applications, a mechanical transmission is generally unstable; when the manufacturing precision is not high, the vibration and noise are noticeable, the realization of stepless transmissions is complex, the cost is high, and the reversing is not flexible. A stutter is obvious during gear switching, and overall operation is troublesome ${ }^{[12-18]}$. An electro mechanical transmission of a transporter has low mechanical strength and transmission power and is mainly suitable for occasions with low speed regulation requirements or power grid coverage; it is not suitable for environments power to shortages, such as in mountainous areas ${ }^{[23,24]}$. This study synthesizes the advantages and disadvantages of the two transmission methods and draws on the design of existing orchard transporters. In this paper, a hydraulic transmission system was used to design a remote-controlled track conveyer driven by hydraulic pressure in a mountain orchard to achieve stepless speed adjustment, stable operation, low consumption, easy to use automatic controls and a complex motion. To meet the requirements of off-grid coverage in mountain orchards, the storage battery was powered by the generator to ensure that the battery was always charged in mountain environments without power. To ensure that the trailer cannot roll over to ensure normal operation and improve safety during transportation over slopes greater than $45^{\circ}$, a T-type tightening wheel and a bell were installed at the bottom of the trailer.

\section{Materials and method}

\subsection{Structure}

The structure of the remote-controlled rail conveyor driven by hydraulic pressure in mountain orchards is shown in Figure $1^{[25,26]}$. It is mainly composed of a control system 1, a conveyor, a supporting track 14 , a trailer 15 , a wire rope 12 , a counterweight 17 and a stroke control device 13 . The control system is used to realize the automatic control of the whole conveyor system. The conveyor is composed of a frame 21 , a diesel engine 2 , a starting device, a hydraulic system, a worm gear 19, a driving wheel 10 and a guide wheel 11. The starting device is composed of an electric motor throttle 5, an electric push rod 4, a pressure reducing valve 3 , a generator 6 and a storage battery 22 . The hydraulic system is composed of a variable piston pump 7 , a hydraulic motor 20 , a control valve block 8 , a fuel tank 9 and auxiliary components. It is used to provide power and change direction. The trailer is connected to the conveyer by the wire rope, and the supporting track is laid along the slope of the orchard by the support frame to guide the conveyer during operation ${ }^{[25]}$. The counterweight tightens the wire rope by gravity to provide the wire rope with sufficient pre-tension. The travel control device controls the limiting position of the transport vehicle movement by the upper stroke switch and the lower stroke switch. The bell 16 rings to alert nearby staff. The anti-derailment device 18 prevents the trailer from derailing and ensures drive safely.

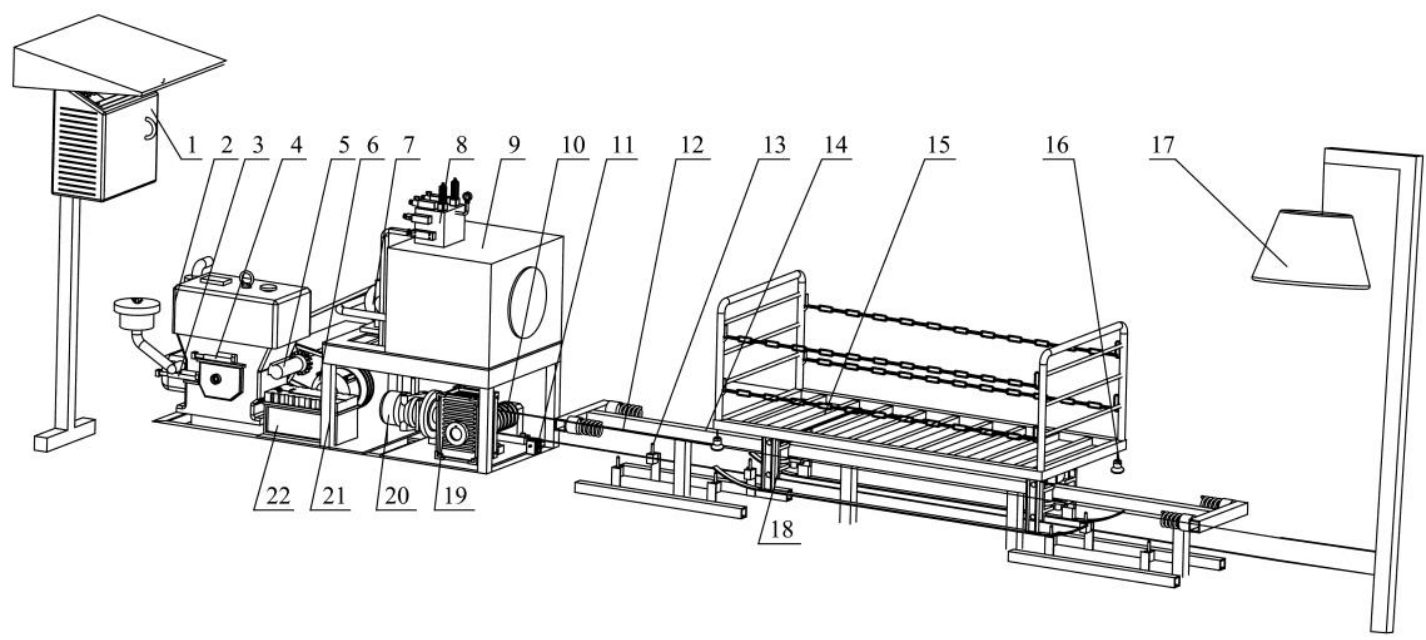

Figure 1 Structure diagram of hydraulic drive rail conveyor for a mountain orchards

\subsection{Working principle}

The diesel engine is started by the starting device as a power source. Before the diesel engine starts, the control system issues the command, the pressure reducing valve and the throttle electric push rod extend, pushing the pressure reducing valve to fully open, and the throttle reaches the preset starting oil level. At this time, the rotation of the electric motor drives the diesel engine to start by gear meshing. After the diesel engine starts, the electric push rod of the pressure reducing valve automatically shrinks and closes the diesel engine pressure reducing valve under the instruction of the control system. Then, the diesel engine transmits the power to the hydraulic pump and the generator through the belt drive. The generator transmits power to the battery, which provides electricity for the whole system. The hydraulic pump delivers the oil to the hydraulic system, and the hydraulic system controls the running route of the hydraulic oil though various hydraulic valves to switch the operating state of the system and achieve the forward and reverse motions and the speed adjustment of the hydraulic motor. The output shaft of the motor is connected with the worm gear through a coupling. The worm gear drives the driving wheel to rotate, and the wire rope is wound on the driving wheel in the shape of an " 8 " and moves along the guide wheel to draw the trailer along the $\operatorname{track}^{[27]}$.

The auxiliary parking baffle is installed at the bottom of the trailer, and the stroke switches are installed at both ends of the track. When the trailer runs to one of the ends of the guide rail, 
the auxiliary parking baffle will touch the travel switch, and the on-off lever of the stroke switch sends a stop signal to the control system to control the hydraulic system oil to flow directly back to the fuel tank, the hydraulic motor stops rotating, and the trailer stops moving.

The control system can accept the control signal from the button on the control panel or the remote controller. According to the signal, it can control the start and stop of the diesel engine, the operation of the throttle, the pressure reducing valve electric push rod, the up and down direction of the transport vehicle, and the start and stop at any point. When an emergency situation is encountered, the entire system will stop immediately if the emergency stop button is pressed.

\subsection{Main technical parameters}

According to the topographic conditions of the mountain orchard and the actual needs of the transport load, the power is calculated based on a maximum slope of $50^{\circ}$ and a load of $1000 \mathrm{~kg}$. An $8.46 \mathrm{~kW}$ diesel engine is used for power. The main technical parameters of the hydraulic-driven remote-controlled orchard transporter are determined as shown in Table 1.

Table 1 Main technical parameters

\begin{tabular}{lc||lc}
\hline \multicolumn{1}{c|}{ Parameter } & Value & \multicolumn{1}{c}{ Parameter } & Value \\
\hline Shape size $/ \mathrm{mm}$ & $1770 \times 700 \times 970$ & Bearing quality $/ \mathrm{kg}$ & $\leq 1000$ \\
Power $/ \mathrm{kW}$ & 8.46 & Climbing angle $/\left(^{\circ}\right)$ & $\leq 50$ \\
Power supply $/ \mathrm{V}$ & 12 & Fuel consumption $/ \mathrm{kg} \cdot \mathrm{h}^{-1}$ & $\leq 1.8$ \\
Running speed $/ \mathrm{m} \cdot \mathrm{s}^{-1}$ & $0.2-1.2$ & Minimum turning radius $/ \mathrm{m}$ & $\leq 3.1$ \\
Total weight $/ \mathrm{kg}$ & $\leq 400$ & System rated pressure $/ \mathrm{MPa}$ & 10 \\
\hline
\end{tabular}

\section{Design of key part}

\subsection{Hydraulic system design}

3.1.1 Composition and working principle of hydraulic system

The hydraulic system is the core component of the remote-controlled track orchard conveyer driven by hydraulic pressure, which is independently developed and designed by the Engineering College of Huazhong Agricultural University. It is mainly composed of a variable piston pump 4, a hydraulic valve block, a hydraulic motor 11, a fuel tank 2, an oil circuit and so on. It mainly carries out energy conversion to address of complex mechanical transmission structures, inflexible power consumption, poor stability and high power demands. The hydraulic system has a simple structure and simplifies the operation process of the transporter to make the operation more convenient and reliable. A schematic diagram of the hydraulic system of the conveyor is shown in Figure 2.

The working principle of the system is as follows. The variable piston pump is driven by the diesel engine 5 to rotate through a belt drive; the pump absorbs oil from the fuel tank through a filter 3 , and the pump outputs pressurized oil $\rightarrow$ electromagnetic proportional speed regulating valve $9 \rightarrow$ three-position four-way electromagnetic directional valve $10 \rightarrow$ hydraulic motor left cavity, driving the worm gear 12, which moves the drive wheel 13 forward; then, the trailer goes up. At this time, the pressurized oil in the right cavity of the hydraulic motor $\rightarrow$ the three-position four-way solenoid valve reversing valve $\rightarrow$ the oil return filter $14 \rightarrow$ the fuel tank. If the spool of the three-position four-way electromagnetic directional valve is changed to the right position, the pressurized oil of the electromagnetic proportional speed regulating valve $\rightarrow$ the three-position four-way electromagnetic directional valve $\rightarrow$ the right cavity of the hydraulic motor will drive the worm gear, moving the drive wheel, and the wheel reverses and the trailer goes down. At this time, the oil in the left chamber of the hydraulic motor $\rightarrow$ the three-position four-way solenoid valve directional valve $\rightarrow$ the oil return filter $\rightarrow$ the fuel tank. The two-position two-way solenoid valve 6 is used to ensure whether there is pressure in the system. When the trailer stops running, the valve port is opened, and the oil directly flows back to the fuel tank through the shortest route to reduce the pressure and the oil temperature. The movement speed of the driving wheel is adjusted by the electromagnetic proportional speed regulating valve, and it cooperates with the relief valve 7 to realize certain functions, such as changing the opening size of the throttle valve to change the flow rate into the hydraulic motor ${ }^{[28]}$. Then, the rotating speed of the hydraulic motor is controlled, and the excess flow output from the hydraulic pump returns to the tank through the relief valve. As an important working parameter in industrial production, the height and temperature of the oil in the fuel tank is measured by level gauge 1 to ensure that the system works normally within the specified requirements. Pressure gauge 8 is used to measure and indicate system pressure. The main role of oil tank is to store oil. In addition, the oil tank has a certain surface area, which can dissipate the heat generated by the oil during the process, remove the dirt in the oil, release the air that has penetrated into the oil, and serve as the installation platform for hydraulic elements and valve blocks ${ }^{[29,30]}$.

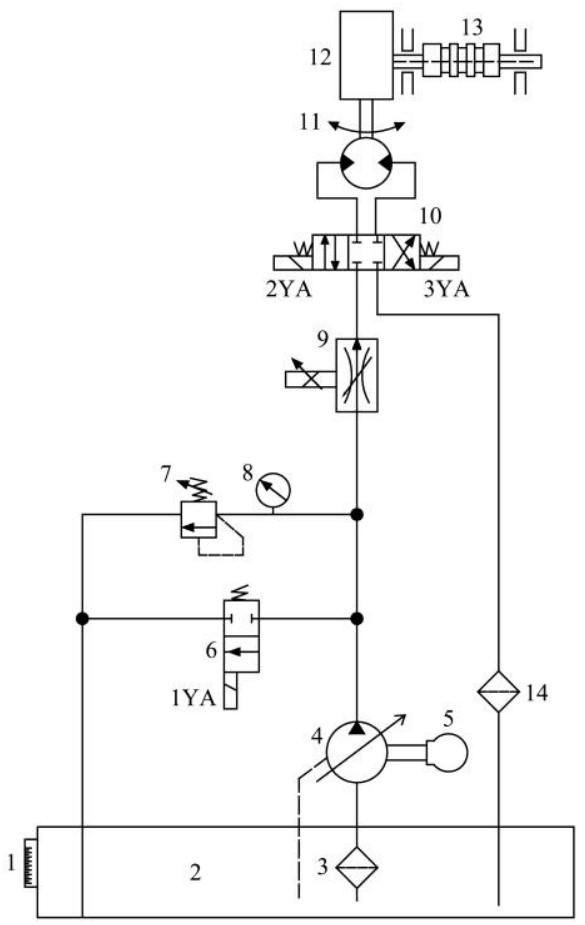

Figure 2 Schematic diagram of the hydraulic system

\subsubsection{Main parameters of the hydraulic system}

The transport vehicle mainly runs along the mountain orchard paths with a maximum slope of $50^{\circ}$. During the operation, the speed of the transport conveyor is controlled by the operator. The maximum speed is $0.8 \mathrm{~m} / \mathrm{s}$, and the acceleration time is 3 seconds. The maximum traction effort of the transport vehicle combines the working load, friction resistance load, inertial load and driving wheel friction ${ }^{[21]}$. The force situation is shown in Figure 3.

The force analysis of the transporter during accelerated climbing is outlined as follows:

$$
\begin{aligned}
F & =\left(F_{L}+F_{f}+F_{a}\right) / \varepsilon \\
& =\left(m g \sin \alpha+\mu m g \cos \alpha+m \frac{\Delta v}{\Delta t} \sin \alpha\right) / \varepsilon
\end{aligned}
$$


where, $F$ is the traction force of the transport vehicle when climbing, $\mathrm{N} ; F_{L}$ is the workload, $\mathrm{N} ; F_{f}$ is the friction resistance load, $\mathrm{N} ; F_{a}$ is inertia load, $\mathrm{N} ; \varepsilon$ is the driving efficiency of the driving wheel; $\mu$ is rolling friction coefficient; $m$ is the maximum load, $\mathrm{kg} ; g$ is the acceleration of gravity; $\alpha$ is the climbing angle, $\left({ }^{\circ}\right) ; \Delta v$ is the maximum speed, $\mathrm{m} / \mathrm{s} ; \Delta t$ is acceleration time, $s$.

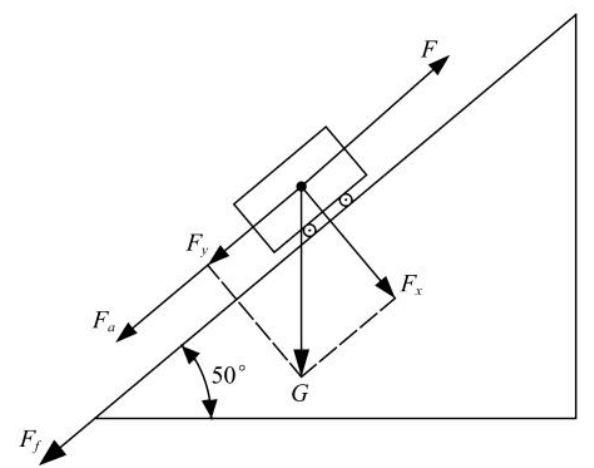

Figure 3 Climbing force analysis

The maximum load, the maximum running speed, the acceleration time of the transport vehicle are $1000 \mathrm{~kg}, 0.8 \mathrm{~m} / \mathrm{s}$ and $3 \mathrm{~s}$. Further, the value of $\varepsilon, \mu, g, \alpha$ are defined as $0.98,0.15$, $9.8 \mathrm{~m} / \mathrm{s}^{2}, 50^{\circ}$ in this study. According to Equation (1), $F=8657 \mathrm{~N}$ can be calculated.

The hydraulic pump and the hydraulic motor are energy conversion devices for the hydraulic system. As power components, the hydraulic pump converts torque $T$ and angular velocity $\omega$ into pressure $p$ and flow $q$, providing enough pressure oil for the hydraulic system, while the hydraulic motor reverses the process. The specific calculation equations are as follows.

$$
\begin{gathered}
T=\frac{F \cdot r}{i} \\
V=\frac{2 \pi T}{\Delta p \eta_{m m}} \\
q=\frac{V n_{\max }}{\eta_{m v}} \\
q_{v}=K \cdot q
\end{gathered}
$$

where, $r$ is the radius of the drive wheel, $\mathrm{m} ; i$ is the worm gear ratio; $V$ is the maximum displacement of motor, $\mathrm{mL} / \mathrm{r} ; \Delta p$ is the pressure difference between the motor inlet and outlet, MPa; $\eta_{m m}$ is the mechanical efficiency of the motor; $q$ is the maximum flow of motor, $\mathrm{L} / \mathrm{min} ; n_{\max }$ is the maximum speed of the motor, $\mathrm{r} / \mathrm{min} ; \eta_{m v}$ is the motor volumetric efficiency; $q_{v}$ is the maximum flow of hydraulic pump, L/min; $K$ is the oil leakage coefficient of the system.

The radius of the driving wheel is $0.09 \mathrm{~m}$, the ratio of worm to worm is 10 , and the pressure difference between the inlet and outlet of the motor is $11 \mathrm{MPa}$. Furthermore, the value of $\eta_{m m}, n_{\max }, \eta_{m v}$, and $K$ are defined as $0.95,995 \mathrm{r} / \mathrm{min}, 0.91$, and 1.1, respectively, in this study. After calculation, $T=78 \mathrm{~N} \cdot \mathrm{m}, q=49 \mathrm{~L} / \mathrm{min}, q_{v}=$ $54 \mathrm{~L} / \mathrm{min}$

\subsection{Control system}

The control system is powered by a $12 \mathrm{~V} / 100$ A DC power supply with a manual panel control circuit and a remote-control circuit $^{[17]}$. Both circuits are composed of a diesel engine pre-start circuit, diesel engine start circuit, throttle addition and subtraction circuit, transport vehicle up circuit, transport vehicle down circuit, stop operation circuit, emergency stop control circuit and limit circuit, all with the same functions. The flow chart of the system is shown in Figure 4.

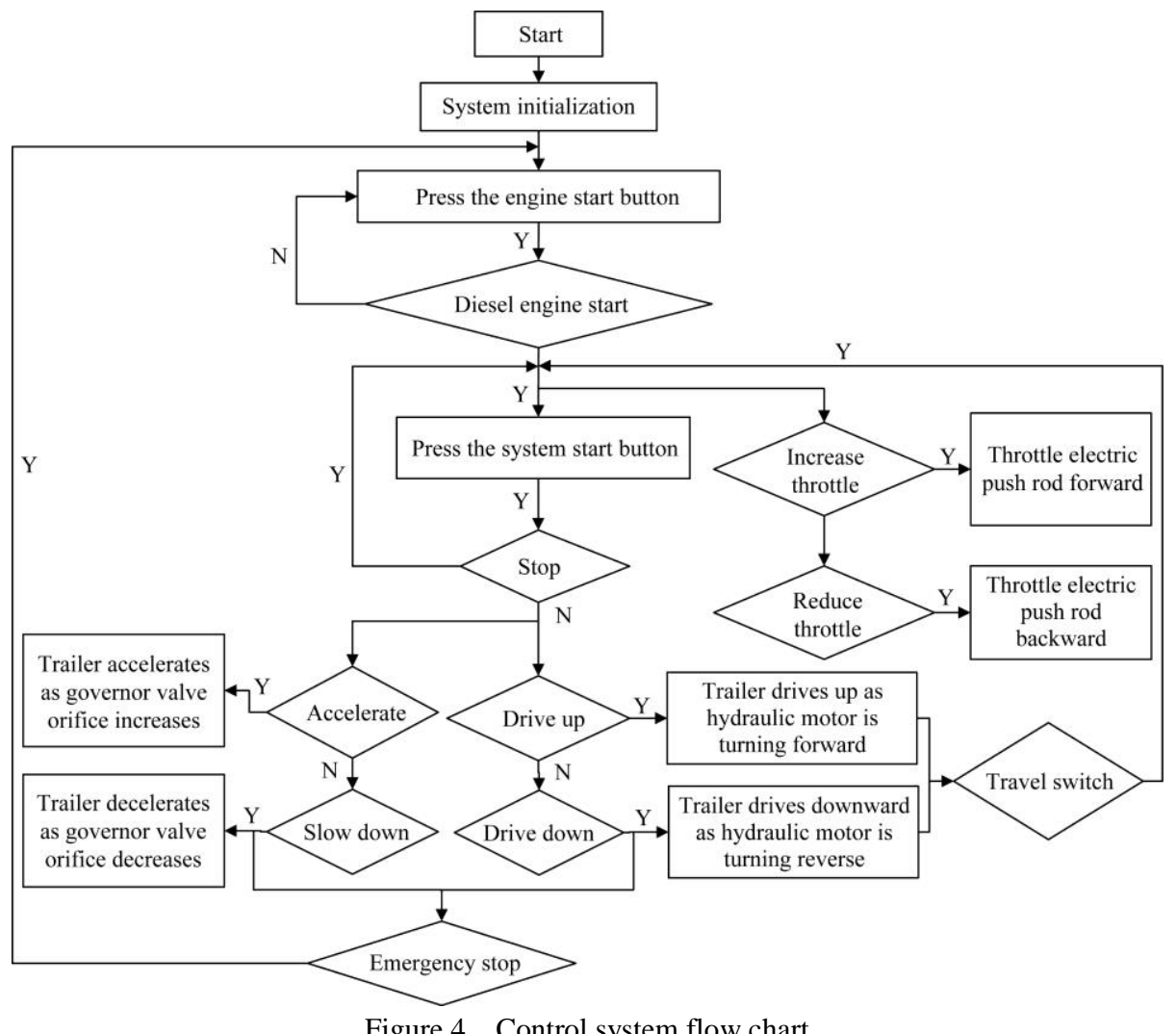

\subsection{Safety protection device}

In the actual transportation process of the orbital orchard transporter driven by the hydraulic system, if an unexpected situation occurs, such as when the maximum static tension of the steel wire rope exceeds the maximum bearing capacity, the steel wire rope will break, and the safety protection device (Figure 5) 
will engage. The steel wire rope and the tension rope 7 are connected in parallel, and the tension rope loses the pre-tension force when the steel wire rope breaks. Then, through the guide movement of pulley 2 and pulley 10, pre-tension spring 3 releases energy and pushes walking wheel brake block 4 to rotate around the pin shaft on bracket 5. The front section of brake pad 4 is inserted directly into the gap between track 8 and walking wheel 6 , and the T-type tightening wheel 9 is squeezed at the bottom of the track to make the trailer stop immediately, to realize emergency braking of the transport vehicle and effectively prevent unnecessary personal injury and property loss caused by the rapid gravity sliding of the transport vehicle. Bell 1, which is attached to the bottom of the trailer, sends out a signal due to the vibration and wind swing during the operation of the trailer. When the trailer moves to any point on the track, people in the vicinity will automatically disperse when they hear the bell, which improves the safety of the remote-controlled rail transporter driven by the hydraulic system and reduces personal harm during the process. The centerline of the T-type tightening wheel and the walking wheel are in the same plane, which prevents the trailer from falling sideways during operation and ensures the smooth operation of the trailer on the track. When the jumping force and climbing angle of the trailer exceed $45^{\circ}$, the upper surface of the extension edge of the T-type tightening wheel is in contact with the bottom surface of the track, to overcome any derailment caused by the undulating jump of the trailer on the track and ensure that the trailer will not overturn because the force parallel to the track is greater than the force perpendicular to the ramp when it is driven along the track under the traction of the wire rope.

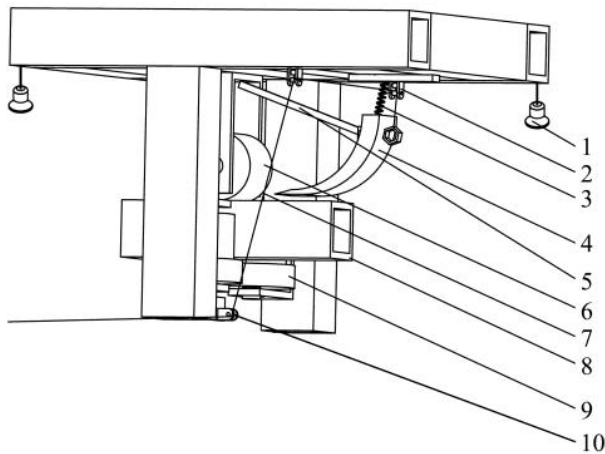

1. Small bell 2,10. Pulley 3. Spring 4. Brake block 5. Brake block bracket 6. Walking wheel 7. Tension rope 8. Track 9. T-type tightening wheel

Figure 5 Structure diagram of the safety and security device

\subsection{Trailer mechanism}

The trailer is a device for placing cargo, as shown in Figure 6. To avoid the trailer tilting during transportation, the trailer was symmetrically designed as a whole and composed of a base, a fence and a chain, with an overall size of $1580 \mathrm{~mm} \times 700 \mathrm{~mm} \times 530 \mathrm{~mm}$. To ensure that the trailer has sufficient rigidity and strength and is economical and practical, it is mainly welded from square steel and steel pipes of different sizes. A removable chain is arranged on the left and right side of the trailer. When loading the goods, one end of the chain is removed to facilitate the workers loading the goods, which also prevents the goods from shifting during the course of transportation. The front and rear of the trailer is provided with a fence, and when the goods are loaded on the trailer, the filled height of the cargo will not exceed the height of the fence. When the trailer is running along the slope, the bottom and side of the goods are in contact with the upper surface of the base and the inner surface of the fence, respectively, and they are placed close to the fence, to ensure that the goods will not spill due to a large slope.
For safer use, the goods and the carriage can be fastened with a binding rope after loading the goods.

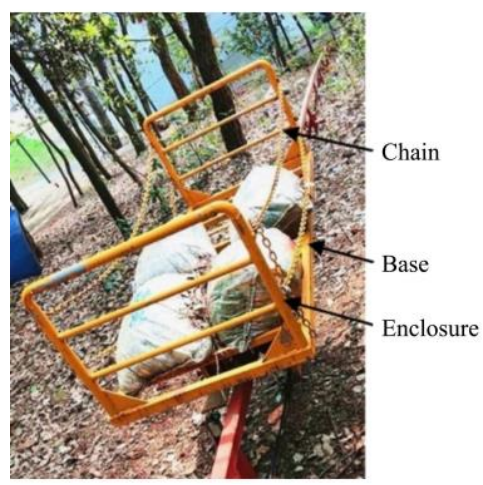

Figure 6 Trailer mechanism

\subsection{Limiting device}

To prevent the transporter from derailing at the end of the $\operatorname{track}^{[13]}$, a limiting device is designed as shown in Figure 7. The limiting device is composed of a stroke switch and a limiting baffle. The limiting switch is installed at both ends of the track, and the limiting baffle is installed under the transport vehicle. In the transport process, when the stroke switch is in contact with the limiting baffle, the limiting switch is closed, the control system of the transporter returns to the neutral position through the three-position four-way solenoid valve, the oil flows directly back to the fuel tank to stop the hydraulic motor, and the transport vehicle stops running at the same time.

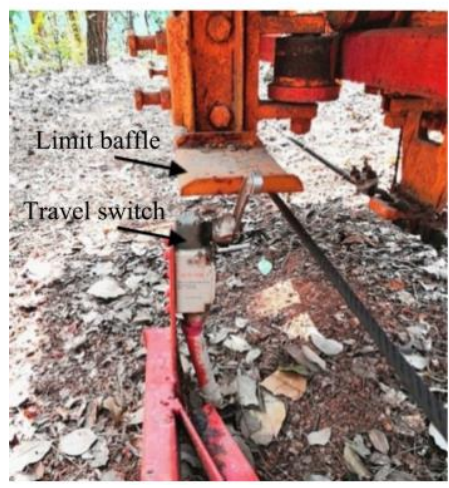

Figure 7 Limiting device

\subsection{Energy storage device}

The energy storage device of the transporter is mainly composed of a lead-acid battery with a rated voltage of $12 \mathrm{~V}$ and a generator $^{[24]}$. As shown in Figure 8, the battery and the generator are installed on the frame of the transporter through the support. The battery has four main functions: 1) to provide electricity for the electric motor; 2) to provide energy for the control system; 3) to provide energy for the valves solenoid valves; 4) to provide energy for the electric push rod. The generator is driven by the diesel engine through the belt drive to charge the battery and ensure that the battery is always charged in the mountain environment.

\subsection{Diesel engine throttle and decompression actuator}

To automatically control the opening and closing state of the pressure relief valve and the throttle size ${ }^{[31]}$, the diesel engine pressure relief valve and throttle actuator were designed as shown in Figure 9. One end of throttle electric push rod 3 is hinged with push rod frame 5 and hinge 4 , the other end is fixed by clamp 2, and the pressure relief valve electric push rod 8 is directly fixed on the push rod frame by screw 9 . Before the pre-start of the diesel engine, the pressure reducing valve push rod extends to move the connecting rod 6 forward, the pressure reducing valve handle 
moves through universal joint 7 to open the pressure reducing valve; the throttle push rod extends to drive spring 1 to stretch, and the spring drives the throttle speed handle to move so that the throttle reaches the preset position to prepare for the start of the diesel engine; after the diesel engine starts, the pressure reducing valve electric push rod automatically retracts to close the pressure reducing valve. During the operation of the transporter, the throttle size is self-adjusted according to the requirements.

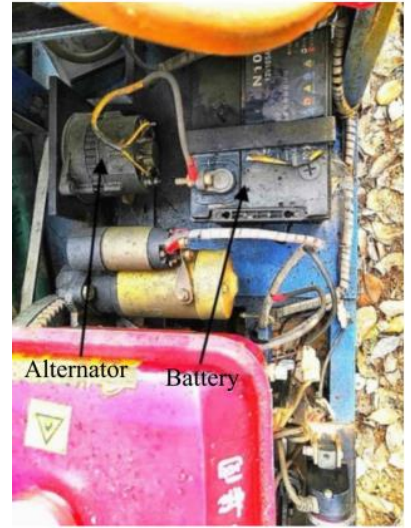

Figure 8 Energy storage device

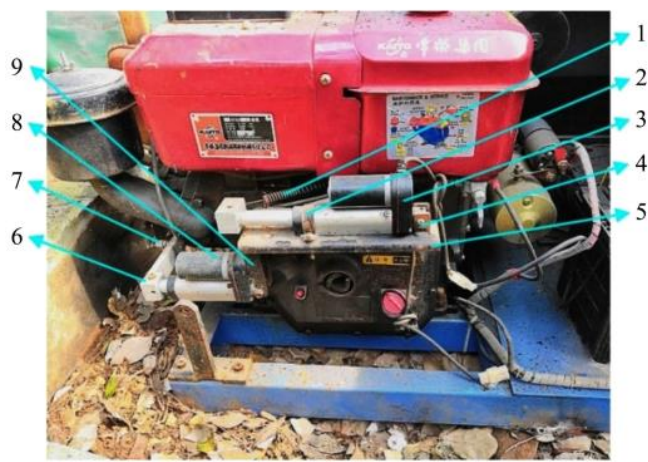

Figure 9 Actuator of diesel engine throttle and pressure reduction valve

\subsection{Counterweight tensioning device}

To provide the steel wire rope with sufficient pre-tensioning force so that it can remain in state of tension ${ }^{[31]}$, the counterweight tensioning device is designed as shown in Figure 9 in this study. One end of tension rope 4 is connected with counterweight 2 , and the other end is connected with fixed slide rail 7 . The counterweight moves on the fixed pulley 1 by pulling the tension rope by gravity, the tension rope is engaged by the connecting pulley 6 , the connecting pulley and the driven pulley 5 are arranged on the slide rail to move forward and backward along the slide rail, and the driven wheel slides backward to tighten the wire rope.

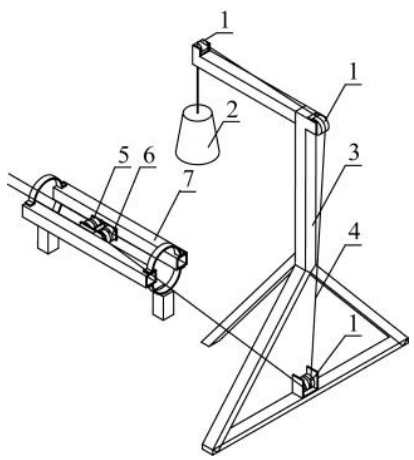

$\begin{array}{llll}\text { 1. Fixed pulley } & \text { 2. Counterweight } & 3 \text {. Frame } & 4 \text {. Tension rope }\end{array}$ 5. Driven wheel 6. Connecting pulley 7. Slide rail

Figure 10 Counterweight tensioner

\section{Testing and data analysis of transporter}

\subsection{Test site and materials}

The experiment was carried out in the mountain orchard transport demonstration garden of Huazhong Agricultural University, and the slope of the demonstration garden was approximately $50^{\circ}$, as shown in Figure 11 . The test equipment includes orchard conveyor, tension sensor, wireless tension node, data processing terminal, ultrasonic flowmeter, electronic scale, sandstone, stopwatch, tape measure, etc. The H3-C3 tension sensor and TQ201 wireless tension node are both produced by Beijing Bichuang Technology Co., Ltd. The range of the tension sensor is $1.0 \mathrm{t}$, and the sensitivity is $2.0000 \pm 0.02 \mathrm{mV} / \mathrm{V}$. The range of the wireless tension node is $\pm 15000 \mu \varepsilon$, and the resolution is $\pm 0.5 \mu \varepsilon$. The tension sensor is connected with the steel wire rope to measure the tension value, and the data are collected through the wireless node and transmitted to the computer. The ultrasonic flowmeter is NS- $2000 \mathrm{H}$ handheld ultrasonic flowmeter produced by Nanjing Pulse Automation Technology Co., Ltd. with an accuracy of $1 \%$, which is used to measure the flow of hydraulic motor. The weight of the trailer is approximately $55 \mathrm{~kg}$, and the test load is bagged sand and gravel. The weight of each bag of sand and gravel is measured by an electronic scale, and the load range is $0-1000 \mathrm{~kg}$, which is increased progressively by $200 \mathrm{~kg}$. There are six load masses tested, namely, $0 \mathrm{~kg}, 200 \mathrm{~kg}, 400 \mathrm{~kg}$, $600 \mathrm{~kg}, 800 \mathrm{~kg}$ and $1000 \mathrm{~kg}$. When the load is $0 \mathrm{~kg}$, it is empty; when the load is $1000 \mathrm{~kg}$, it is full ${ }^{[20]}$. According to the equation $v=s / t$, the running speed is calculated, and then the average speed is calculated by the equation $v_{0}=\sum v / n$.

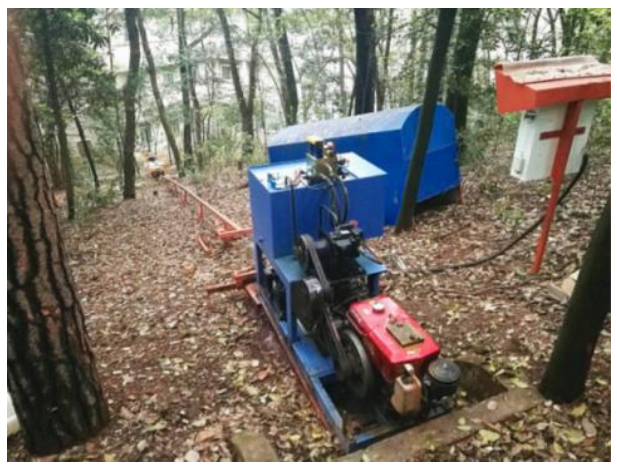

Figure 11 Mountain orchard transporter

\subsection{Functional test of the transporter}

The functions of each part of the conveyer are tested by the manual panel and remote control, and the uplink, downlink, braking, emergency stopping, and limit position automatic stopping functions of the trailer can be implemented at any point on the track. After inspection, the transport conveyor achieved the functions of diesel engine starting under two control modes, trailer moving up and down, instant braking at any point, emergency stopping, frequent reversing, uniform movement and automatic stopping at the limiting position after the trailer starts accelerating evenly, which met the design requirements.

\subsection{Driving speed test}

The track length was measured with a tape measure; the unit of measurement was accurate to the decimeter level, and the measured track length was approximately $17 \mathrm{~m}$. A stopwatch was used to measure the time required for the trailer to run up and down under different load conditions, and the measurement time was accurate to $0.01 \mathrm{~s}$. The rotational speed of the hydraulic pump was measured by a tachometer, which was accurate to $0.1 \mathrm{r} / \mathrm{s}$ to ensure 
the same flow rate of the hydraulic pump. The pressure of the hydraulic circuit was measured with a pressure gauge to an accuracy of $0.1 \mathrm{MPa}$. Ten tests were carried out on the uphill and downhill sides of each load. According to the equation $v=s / t$, the running speed was calculated, the average speed was calculated by the equation $v_{0}=\sum v / n$, and the correlations between the driving speed, load and system pressure were tested. The uplink and downlink running speed and system pressure test results of the transport vehicle under different loads are shown in Table 2.

It can be seen from Table 2 that with the continuous increase in the load, the system pressure increases gradually when the trailer goes uphill, from 5.9 to $10.0 \mathrm{MPa}$, and the running speed of the transporter decreases gradually, from 0.76 to $0.00 \mathrm{~m} / \mathrm{s}$. When the trailer goes downhill, the system pressure decreases gradually, from 5.3 to $3.2 \mathrm{MPa}$, and the running speed of the transport vehicle increases gradually, from 0.79 to $1.08 \mathrm{~m} / \mathrm{s}$. When the uphill load is $1000 \mathrm{~kg}$, the system pressure is $10.0 \mathrm{MPa}$, which exceeds the rated pressure of the system. The overflow valve in the hydraulic system is opened, and the oil flows directly back to the fuel tank through the oil pipe. At this time, the transport vehicle does not move upward. When going downhill, with the increasing load, the gravity of the fruit itself is partially converted into energy to carry the fruit, resulting in the gradual decrease of system pressure and the gradual increase in the running speed of the transport vehicle, which is within the safe driving speed range. The minimum traveling speed of the trailer is $0.29 \mathrm{~m} / \mathrm{s}$ when the uphill load is $0-800 \mathrm{~kg}$, and the traveling speed is $0.79-1.08 \mathrm{~m} / \mathrm{s}$ when the downhill load is $0-1000 \mathrm{~kg}$, which all meet the design requirements for the traveling speed of the transporter in Table 1. The $R^{2}$ correlation among the load quality of the trailer, the driving speed and the system pressure is above 0.90 , which indicates that the driving speed and the system pressure are greatly affected by the load quality.

Table 2 Velocity and system pressure of transporter under different loads

\begin{tabular}{cccccc}
\hline \multirow{2}{*}{ Load $/ \mathrm{kg}$} & \multicolumn{2}{c}{ Vehicle speed $/ \mathrm{m} \cdot \mathrm{s}^{-1}$} & & \multicolumn{2}{c}{ System pressure/MPa } \\
\cline { 2 - 5 } & $\mathrm{Up}$ & Down & $\mathrm{Up}$ & Down \\
\hline 0 & 0.76 & 0.79 & 5.9 & 5.3 \\
200 & 0.66 & 0.86 & 7.6 & 4.9 \\
400 & 0.61 & 0.93 & 8.4 & 4.5 \\
600 & 0.52 & 0.96 & 9.2 & 4.1 \\
800 & 0.29 & 1.00 & 9.8 & 3.7 \\
1000 & 0.00 & 1.08 & 10.0 & 3.2 \\
$R^{2}$ & 0.9029 & 0.9817 & 0.9260 & 0.9984 \\
\hline
\end{tabular}

\subsection{Maximum load test}

In the allowable range of $0.2-1.2 \mathrm{~m} / \mathrm{s}$, it is necessary to measure the maximum carrying capacity of the transporter, and when the maximum carrying capacity is reached, the motor flow rate and the wire rope pulling force were measured by using ultrasonic flowmeter and force sensor. On the basis of the upslope load of $800 \mathrm{~kg}$ and downslope load of $1000 \mathrm{~kg}$, the load increased by $10 \mathrm{~kg}$. Finally, when the maximum uphill load is $840 \mathrm{~kg}$, the running speed is $0.2 \mathrm{~m} / \mathrm{s}$, the wire rope tension is $7451 \mathrm{~N}$, and the flow rate of hydraulic motor is $43 \mathrm{~L} / \mathrm{min}$, and when the maximum downhill load is $1100 \mathrm{~kg}$, the running speed is $1.2 \mathrm{~m} / \mathrm{s}$, the wire rope tension is $8650 \mathrm{~N}$, and the flow rate of hydraulic motor is $49 \mathrm{~L} / \mathrm{min}$. The driving speed reaches the designed maximum and minimum respectively. However, the wire rope pulling force and motor flow rate are less than the theoretical calculation values $F=8657 \mathrm{~N}$ and $q=49 \mathrm{~L} / \mathrm{min}$. The reason is that there are certain transmission losses in belt drive, hydraulic drive, worm gear and worm drive in the equipment, and there are production, installation errors, system heating, leakage and so on in each hydraulic component, which leads to the difference between test results and theoretical results; and there is little difference between the downhill wire rope tension and the motor flow rate and the theoretical calculation value, because the gravity of the fruit itself is transformed into the power to carry the fruit when downhill, which makes the motor output normal.

\subsection{Remote control distance test}

The remote control KGS-B10-1T6 and signal receiver were used to test the remote-control distance in the Huazhong Agricultural University Citrus Orchard and Hubei Yichang Citrus Orchard. If the corresponding indicator of the receiver is on after the remote control sends out the signal, it means that the signal is effectively transmitted. The remote-control distance was measured using a tape measure. The main factors considered in the experiment include vegetation density, vegetation height, whether the remote-control antenna is pulled out, and the height of the receiver. The planting amount of citrus trees per hectare in China ranges from 800 to 1600 , the average height of the citrus trees is less than $3 \mathrm{~m}$, and the installation height of the control system is approximately $1.5 \mathrm{~m}$, so the limit is $3 \mathrm{~m}$ when adjusting the height of the receiver. Table 3 shows that when the receiver height is $1.5 \mathrm{~m}$ lower than the vegetation height, the effective remote-control distance is $115-235 \mathrm{~m}$. The shorter the effective transmission distance is, the higher the vegetation density is, and the greater the influence on the remote-control distance. When the receiver installation height is $3.5 \mathrm{~m}$, it is higher than the height of the vegetation, the effective remote control distance is 260$455 \mathrm{~m}$, and the effective distance increases greatly and is not affected by the vegetation density. When the vegetation is the same height as the receiver, the remote-control distance is greatly increased when the antenna is pulled out. Therefore, it is concluded that the remote control distance is closely related to the size of fruit trees in citrus orchard, the density of vegetation and whether the remote control antenna is pulled out. So when the remote control is used to control the transport conveyor, the control box should be installed higher than the height of the fruit trees while the antenna is pulled out.

Table 3 Test results of remote control distance

\begin{tabular}{|c|c|c|c|c|c|}
\hline Test site & Vegetation density/trees $\cdot \mathrm{hm}^{-2}$ & Vegetation height $/ \mathrm{m}$ & Receiver height $/ \mathrm{m}$ & Pull-out antenna & Effective distance/m \\
\hline \multirow{4}{*}{$\begin{array}{l}\text { Yichang Orange Garden, } \\
\text { Hubei Province }\end{array}$} & \multirow{4}{*}{$900-1100$} & \multirow{4}{*}{$2.5-3$} & 1.5 & No & 115 \\
\hline & & & 1.5 & Yes & 220 \\
\hline & & & 3.5 & No & 260 \\
\hline & & & 3.5 & Yes & 455 \\
\hline \multirow{3}{*}{$\begin{array}{l}\text { Orange Garden of Huazhong } \\
\text { Agricultural University }\end{array}$} & \multirow{3}{*}{$800-900$} & \multirow{3}{*}{$2.5-3$} & 1.5 & No & 125 \\
\hline & & & 1.5 & Yes & 235 \\
\hline & & & 3.5 & Yes & 455 \\
\hline
\end{tabular}




\section{Conclusions}

Based on existing orchard transporters with mechanical and electromechanical transmissions, this research designed and produced a hydraulically driven remote-controlled orchard transporter for mountain orchards. Through various functions, driving speeds, remote control distances and other tests, the operational parameters of the transporter were tested. The following conclusions were drawn:

(1) The remote-controlled orchard transporter driven by hydraulics has a comprehensive function and simple operation. On the basis of small-range speed regulation, the functions of forward, backward and stop can be realized, the three states can be switched arbitrarily, and the emergency stop operation can be carried out in an emergency. It can be controlled by manual panels and remote-control systems during operation, both of which have the same function. The test shows that the maximum climbing angle is $50^{\circ}$, the average running speed is $0.77 \mathrm{~m} / \mathrm{s}$, the maximum uphill load is $840 \mathrm{~kg}$, the maximum downhill load is $1100 \mathrm{~kg}$, the rated pressure of the system is $10 \mathrm{MPa}$, and the maximum remote control distance is $455 \mathrm{~m}$, which meets the design requirements.

(2) The transport conveyor relies on a diesel engine to drive a set of hydraulic systems with volume and speed regulation and drives the trailer with a driving wheel. The power supply of the diesel engine start-up, control system and solenoid valve can be provided by a $12 \mathrm{~V}$ battery, which addresses the use of transport conveyors in areas that need power grid coverage.

(3) The $R^{2}$ correlations among the load quality of the trailer, the travel speed and the system pressure are above 0.90, the driving speed and system pressure are greatly affected by the load, especially when the load is too large, and the climbing speed is slow, which is not conducive to improving work efficiency. The efficiency of hydraulic transmission and worm gear transmission is lower than that of mechanical transmission. Low-speed high-torque motors and hydraulic brakes should be introduced to improve transmission efficiency in the future.

(4) In order to solve the problem of orchard mechanization, in the future research, we should consider how to carry other orchard agricultural machinery combined operation conveniently on the basis of the existing hydraulic-driven remote-controlled rail transporter, such as orchard pruning machinery and orchard picking machinery, so as to improve the level of orchard production mechanization.

\section{Acknowledgements}

The authors acknowledge that this work was supported by the National Key R\&D Program (Grant No. 2020YFD1000101), Special Funds for the Construction of Industrial Technology System of Modern Agriculture (Citrus) (Grant No. CARS-26), Construction Project of Citrus Whole Course Mechanized Scientific Research Base (Agricultural Development Facility [2017] 19), Hubei Agricultural Science and Technology Innovation Action Project, Young Innovative Talents Project of General Colleges and Universities in Guangdong Province (Grant No. 2018KQNCX311), Science and Technology Program of Guangdong Polytechnic College (Grant No. JXGG202030).

\section{[References]}

[1] Zou B L, Liu F L, Zhang Z B, Hong T S, Wu W B, Lai S X.
Mechanization of mountain orchards: development bottleneck and foreign experiences. Journal of Agricultural Mechanization Research, 2019; 41(9): 254-260. (in Chinese)

[2] Pu Y J, Toudeshki A, Ehsani R, Yang F Z. Design and evaluation of a two-section canopy shaker with variable frequency for mechanical harvesting of citrus. Int J Agric \& Biol Eng, 2018; 11(5): 77-87.

[3] Wu W B, Zhao B, Zhu Y Q, Wang H L, Zhi L, Feng Z F. Research progress of hilly orchard transporter. Journal of Huazhong Agricultural University, 2013; 32(4): 135-142. (in Chinese)

[4] Lü Q, Cai J R, Liu B, Deng L, Zhang Y J. Identification of fruit an branch in natural scenes for citrus harvesting robot using machine vision and support vector machine. Int J Agric \& Biol Eng, 2014; 7(2): 115-121.

[5] Giuseppe M, Emanuele C, Rita P, Roberta S, Biagio P. Performance evaluation of digestate spreading machines in vineyards and citrus orchards preliminary trials. Heliyon, 2020, 6: e04257. doi: 10.1016/ j.heliyon.2020.e04257.

[6] Zhao Y, Xiao H R, Mei S, Song Z Y, Ding W Q, Jing Y, et al. Current status and development strategies of orchard mechanization production in China. Journal of China Agricultural University, 2017; 22(6): 116-127. (in Chinese)

[7] Bagheri N, Bordbar M. Factor analysis of agricultural mechanization challenges in Iran. Agriculrural Engineering International: CIGR Journal, 2014; 16(1): 167-172.

[8] Zhang B, Zhang L X, Fu Z T, Wang J Q. Analysis on agricultural organizations' application requirements for agricultural machinery and factors affecting purchasing behavior. Journal of Agricultural Mechanization Research, 2018; 40(5): 10-17. (in Chinese)

[9] Sheng L L, Song S R, Hong T S, Li Z, Dai Q F. The present situation and development and development of mountainous orchard mechanization in Guangdong province. Journal of Agricultural Mechanization Research, 2017; 39(11): 257-262. (in Chinese)

[10] Hong T S, Su J, Zhu Y Q, Yang Z, Yue X J, Song S R. Circular chain ropeway for cargo transportation in mountain citrus orchard. Transactions of the CSAM, 2011; 42(6): 108-111. (in Chinese)

[11] Wen T, Hong T S, Su J, Zhu Y Q, Kong F B, Chileshe J M. Tension detection device for circular chain cargo transportation ropeway in mountain orchard. Transactions of the CSAM, 2011; 42(8): 80-84. (in Chinese)

[12] Li S J, Xing J J, Zhang Y L, Meng L, Fan Q Z. 7YGS-45 type self-propelled dual-track mountain orchard transport. Transactions of the CSAM, 2011; 42(8): 85-88. (in Chinese)

[13] Li S J, Xing J J, Zhang Y L, Li X J, Fan Q Z. Construction of 7YGS-45 type orchard transport automatic control test platform. Advanced Materials Research, 2011; 1169: 1396-1401.

[14] Li X J, Zhang Y L, Zhang W Y, Ling X P. Design and improvement of the remote control self-propelled monorail transporter for mountainous orchard. Journal of Huazhong Agricultural University, 2014; 33(5): 117-122. (in Chinese)

[15] Zhang J F, Li J Y, Zhang Y L, Li S J, Meng L. Design of remote control monorail transporter for mountainous orchard. Transactions of the CSAM 2012; 43(2): 90-94. (in Chinese)

[16] Shamshiri R R, Weltzien C, Hameed I A, Yule I J, Grift T E, Balasundram $\mathrm{S} \mathrm{K}$, et al. Research and development in agricultural robotics: A perspective of digital farming. Int J Agric \& Biol Eng, 2018; 11(4): 1-14.

[17] Meng L, Zhang Y L, Zhang W Y, Li J, Li S J, Li M Z. Design of trailed trackless mountain orchard transporter with remote control. Journal of Huazhong Agricultural University, 2015; 34(4): 125-129. (in Chinese)

[18] Zhang J F, Zhang T J, Zhang Y L. Design of the remote control traction transporter for mountainous orangery. Hubei Agricultural Sciences, 2012; 51(10): 2111-2113, 2131. (in Chinese)

[19] Li S J, Liu H, Zhang Y L, Che H, Meng L, Ma P Y, et al. Optimization of rack tooth forms of monorail mountain orchard transporter. Transactions of the CSAM, 2018; 34(6): 52-57. (in Chinese)

[20] Li H, Li S J, Zhang Y L, Ma P Y, Chen M. Mechanical simulation and experiment of self-propelled monorail mountain orchard transporter under different racks. Journal of Huazhong Agricultural University, 2019; 38(2): 114-122. (in Chinese)

[21] Liu Y, Li Z, Hong T S, Lu S L, Song S R, Huang S P. Design of drive system for battery-drive monorail transporter for mountainous orchard Transactions of the CSAM, 2017; 33(19): 34-40. (in Chinese)

[22] Raheleh F, Alireza K, Seyyed S M. Estimation of a mechanization index 
in apple orchard in iran. Journal of Agricultural Science, 2010; 2(4): $180-185$.

[23] Tang X L. Design of 7YGD-45 type single-track orchard transport. Wuhan: Huazhong Agricultural University, 2012. (in Chinese)

[24] Li Z, Hong T S, Sun T B, Ou Y Y P, Luo Y Q. Design of battery powered monorail transporter for mountainous orchard. Journal of Northwest A \& F University (Nat. Sci. Ed.), 2016; 44(6): 221-227, 234. (in Chinese)

[25] Huazhong Agricultural University. A hydraulically driven remote control rail transport device. Chinese Patent, 2017213508586, 2018-06-01.

[26] Huazhong Agricultural University. Hydraulically driven remote control rail transportation system and control method. Chinese Patent, 2017109804914. 2018-02-27.

[27] Li S J. Characteristic analysis and experimentation study on driving wheelset of self-propelled dual-track orchard transport. Wuhan: Huazhong Agricultural University, 2012. (in Chinese)

[28] Song W, Li Y F, Zhang H B, Wang D H. Design of control and hydraulic drive system for high-altitude live working vehicle. The Journal of Engineering, 2019; 2019(23): 8561-8565.

[29] Tomarov G V, Nikolaev A E, Semenov V N, Shipkov A A, Shepelev S V. Study of the causes and identification of the dominant mechanisms of failure of bellows expansion joints used in district heating system pipelines at MOEK. Thermal Engineering, 2015; 62(6): 456-463.

[30] Liu Y G, Gao X H, Pei Z C, Zhang H. Research of impact load in large electrohydraulic load simulator. Mathematical Problems in Engineering, 2014.

[31] Zhang J F. Research on remote control key technology and device of mountain orchard monorail transporter. Wuhan: Huazhong Agricultural University, 2012. (in Chinese) 